\title{
A EXPERIÊNCIA DE UM CONSELHO REGIONAL DE DESENVOLVIMENTO - COREDE - NO ESTADO DO RIO GRANDE DO SUL
}

\author{
L. V. ÁVILA'; C.C WESENDOCK²; L.R.R.G MADRUGA'; J.S.T. DA SILVEIRA'; ${ }^{3}$ R.B. DA SILVA ${ }^{4}$ \\ ${ }^{1}$ Universidade Federal de Santa Maria - PPGA - UFSM \\ 2 Universidade Estadual do Rio Grande do Sul - UERGS \\ ${ }^{3}$ Universidade Regional Integrada - PPGGEO - URI \\ ${ }^{4}$ Instituto Federal Farroupilha - Campus de São Vicente do Sul \\ admlucasveiga@gmail.com'; cw@hotmail.com²; lucia.rejane@hotmail.com'; joaotusi@hotmail.com e \\ belmonte@svs.iffarroupilha.edu.br ${ }^{4}$
}

Artigo submetido em Fevereiro/2013 e aceito em março/2013

\section{RESUMO}

Este artigo relata à experiência do Conselho Regional de Desenvolvimento do Vale do Jaguari/RS na elaboração do Planejamento Estratégico Regional, tentando associála à ótica dos modelos de desenvolvimento de Barquero (2001) e Boisier (1995), desde o diagnóstico das potencialidades e carências apresentadas pela região e discutidas amplamente, principalmente pela equipe técnica e lideranças dos municípios abrangidos. No que se refere ao desenvolvimento regional, recomenda-se que os gestores públicos atuem com visão estratégica, envolvendo os atores regionais no desenvolvimento de ações conjuntas. Também, ressalta-se que as iniciativas de desenvolvimento devem começar particularmente em cada região, potencializando os fatores locais e promovendo sinergia de esforços no sentido de desenvolver novas fontes de recursos e possibilidades para o desenvolvimento regional.

PALAVRAS-CHAVE: Desenvolvimento Regional; COREDE; Vale do Jaguari.

\section{THE EXPERIENCE OF JAGUARI / RS VALLEY DEVELOPMENT REGIONAL COUNCIL AND THEIR RELATIONSHIP WITH DEVELOPMENT MODELS}

\begin{abstract}
This paper reports the experience of the Regional Development Council Valley Jaguari / RS in preparing the Regional Strategic Planning, trying to link it to the perspective of development models Barquero (2001) and Boisier (1995), from diagnosis and the potential deficiencies presented and discussed widely by region, mainly by the technical staff and leadership of the municipalities covered. Regarding regional
\end{abstract}

development, it is recommended that public managers act with strategic vision, involving regional stakeholders in developing joint actions. Also, it is emphasized that development initiatives must begin in each particular region, boosting the local factors and promoting synergy of efforts to develop new funding sources and opportunities for regional development.

KEY-WORDS: Regional Development; COREDE; Jaguari Valley. 


\section{A EXPERIÊNCIA DE UM CONSELHO REGIONAL DE DESENVOLVIMENTO - COREDE - NO ESTADO DO RIO GRANDE DO SUL}

\section{INTRODUÇÃO}

No Brasil, as primeiras experiências de planejamento visando o desenvolvimento local, regional e nacional foram implementadas pelo governo federal em meados da década de 1930, com foco no crescimento econômico. No final de 1950, o governo central criou a SUDENE Superintendência de Desenvolvimento do Nordeste e, em 1970, as Superintendências de Desenvolvimento do Centro-Oeste - SUDECO, e da Região Sul - SUDESUL. Na década de 1980, o governo central manifestava interesse na promoção do planejamento e do desenvolvimento regional, mas viu-se forçado a concentrar seus esforços em ações e problemas emergentes na época, relacionados à crise econômica e ao ajuste estrutural enfaticamente sugerido pelos organismos financeiros internacionais. A década de 1990 foi caracterizada pela mudança de comportamento na política governamental, consoante às estratégias de planejamento e desenvolvimento. Segundo Bresser Pereira (1995, p.12), a reforma realizada neste período deve ser entendida dentro do contexto da redefinição do papel do Estado, que deixou de ser o responsável direto pelo desenvolvimento econômico e social pela via da produção de bens e serviços, para fortalecer-se na função de promotor e regulador desse desenvolvimento.

Com a recente troca de governo de Yeda Crusius (2007-2010) para o governo de Tarso Genro (2011-2014) não ocorreram mudanças significativas no processo. Porém, foi instituído o Conselho Estadual de Desenvolvimento, composto por 50 lideranças regionais (Prefeitos, vereadores, presidentes de associações e sindicatos, representantes e líderes regionais, docentes de universidades, agentes municipais etc.) oriundas dos mais diversos segmentos, com a função assessorar diretamente o Governador do Estado em questões estratégicas. O Governo Federal, por sua vez, redirecionou sua política de desenvolvimento regional para ações que envolvem mesorregiões ${ }^{1}$. Nesse contexto, as políticas estratégicas estaduais assumem um papel de grande importância no cenário microrregional. O planejamento do desenvolvimento microrregional passa a assumir uma visão estratégica, ao invés do atendimento de emergências e urgências de curto prazo, ou seja, estrutura-se na perspectiva da construção de um modelo de desenvolvimento sustentável em médio e longo prazo.

Nessa nova configuração, as diversas regiões passam a ser o epicentro analítico e explicitador das demandas e principais deficiências que entravam o seu desenvolvimento. Este estudo descreve à experiência do Conselho Regional de Desenvolvimento do Vale do Jaguari/RS na elaboração do Planejamento Estratégico Regional, tentando associá-la à ótica dos modelos de desenvolvimento de Barquero (2001) e Boisier (1995), desde o diagnóstico das potencialidades e

\footnotetext{
1 As mesoregiões foram criadas pelo Ministério da Integração Nacional (com base em 13 Programas de Desenvolvimento Integrado e Sustentável de Mesorregiões Diferenciadas - PROMESO). tendo como fundamento e orientação a Política Nacional de Desenvolvimento Regional - PNDR, institucionalizada pelo Decreto no 6.047 , de 22 de fevereiro de 2007, com o objetivo de reduzir as desigualdades de nível de vida entre as regiões brasileiras e promover a equidade no acesso a oportunidades de desenvolvimento. Estão distribuídas por todo o país, como espaços sub-regionais de confluência entre dois ou mais estados ou de fronteira com países vizinhos.
} 
carências apresentadas pela região e discutidas amplamente, principalmente pela equipe técnica e lideranças dos municípios abrangidos.

\title{
O MODELO DE ANÁLISE DAS TIPOLOGIAS DOS SISTEMAS LOCAIS DE PRODUÇÃO
}

Podem-se explicitar estratégias de desenvolvimento através dos sistemas locais de produção, os quais possuem caracterizações conforme sua história, evolução, organização institucional, contextos sociais e culturais nos quais se inserem, estrutura produtiva, organização industrial, formas de governança, logística, associativismo, cooperação entre agentes, formas de aprendizado e grau de disseminação do conhecimento local especializado.

Segundo Barquero, a estratégia de desenvolvimento tem por objetivo:

\begin{abstract}
converter o território em um entorno inovador, no qual a capacidade empresarial e organizacional, bem como as respostas inovadoras das empresas e dos atores locais, trouxesse resultados positivos no contexto em que compete a cidade ou região. Para tanto, seria preciso dar enfase as acões que potencializam os pontos fortes e neutralizam os pontos fracos do território. Algumas dessas ações estariam mais voltadas para a inovação, através do fomento a difusão da tecnologia e da interação inovadora envolvendo os atores locais, enquanto outras estariam mais comprometidas com a capacitação empresarial e a organização produtiva do território (2001, p. 119).
\end{abstract}

Todavia, países em desenvolvimento com grandes extensões territoriais, como é o caso do Brasil, exibem desigualdades regionais que necessitam de políticas específicas adequadas para cada tipo de situação. Os diferentes locais, regiões e territórios devem ser estudados em função de suas características específicas, as quais deveriam reunir organismos governamentais, unidades produtivas, universidades, associações de produtores, sindicatos de trabalhadores e centros de pesquisa, visando à elaboração de propostas e planos de desenvolvimento local ou regional, de maneira a contemplar e consolidar uma estrutura de crescimento autossustentável com geração de processos inovadores. Tolosa (1972) enfatiza a necessidade de se considerar nos modelos de desenvolvimento o aspecto de dimensão espacial, ou seja, sugere políticas de desenvolvimento que atendam aos problemas oriundos dos desequilíbrios setoriais espaciais.

Conforme Barquero (2001) o desenvolvimento acontece a partir da utilização da potencialidade e do excedente gerado localmente e, em casos mais raros, pela atração de recursos externos ao processo produtivo local. O referido pesquisador aponta a criação e difusão de inovações no sistema produtivo, a organização flexível da produção, a flexibilidade e o fortalecimento das instituições, a geração de economias de aglomeração e de economias de diversidade nas cidades (desenvolvimento urbano do território), como fatores determinantes do crescimento endógeno. Aliando-se a noção de sistemas locais de produção com estratégias de desenvolvimento, Barquero propõe a tipologia dos sistemas locais de produção (Figura 1) para diagnosticar as deficiências e carências e potencializar o desenvolvimento local/regional. 


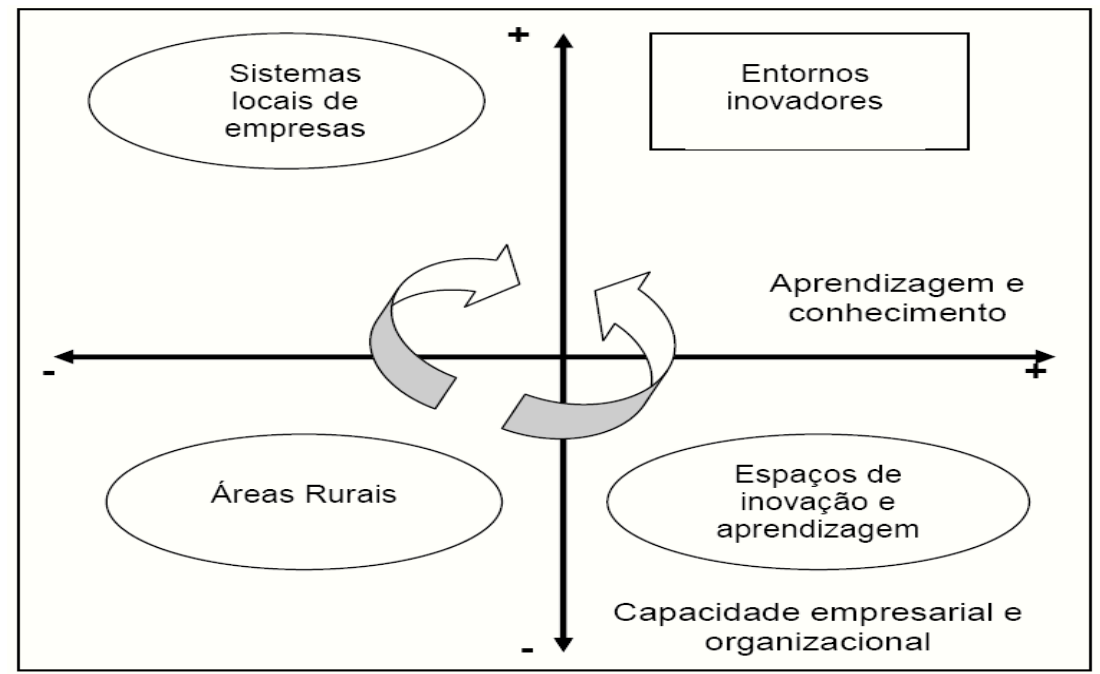

Figura 1 - Tipologia dos sistemas locais de produção

Fonte: Barquero (2001, p.65)

Em geral, um sistema local de produção comporta um conjunto de empresas com capacidades relacionadas ou afins e de portes variados. Essas empresas, por sua vez, atraem fornecedores e outras indústrias correlatas e de apoio, cuja presença e importância nos sistemas locais são determinadas pelas forças de mercado.

Pelo potencial que apresentam do ponto de vista de políticas de desenvolvimento regional/local, e mesmo de políticas industriais, as aglomerações geográficas e setoriais de empresas têm sido objeto de estudos e de medidas de políticas públicas no Brasil e no exterior. Todavia, no caso do Brasil, utilizam-se critérios metodológicos que permitem identificar, delimitar geograficamente e caracterizar sistemas ou arranjos produtivos locais, segundo alguns tipos básicos, de acordo com sua relevância para o desenvolvimento regional/local e sua importância no respectivo setor ou classe de indústria. Este procedimento é fundamental para nortear o direcionamento das políticas e ações públicas. E é nesse sentido que este trabalho pretende contribuir para o aperfeiçoamento do processo de desenvolvimento dos municípios circunscritos ao COREDE do Vale do Jaguari.

\section{DESENVOLVIMENTO ENDÓGENO VERSUS DESENVOLVIMENTO REGIONAL}

A teoria do desenvolvimento endógeno, segundo Barquero, compreende o desenvolvimento local como:

um processo de crescimento e mudança estrutural que ocorre em razão das transferências de recursos das atividades tradicionais para as modernas, bem como pelo aproveitamento das economias externas e pela introdução de inovações, determinando a elevação do bem-estar da população de uma cidade ou região. Quando a capacidade local é capaz de utilizar o potencial de desenvolvimento e liderar o processo de mudança 
estrutural, pode-se falar de desenvolvimento local endógeno ou, simplesmente, de desenvolvimento endógeno (2001, p.57).

A complexidade dessa conceituação reside no fato de agrupar as principais contribuições das teorias econômicas que colaboraram para o debate do desenvolvimento regional no último século. Das contribuições da grande teoria do desenvolvimento e da teoria do desenvolvimento dualista, a teoria do crescimento endógeno reteve os mecanismos de acumulação e crescimento das economias de mercado; da teoria de dependência, extraiu a visão sistêmica ou estruturalista, isto é, a necessidade de inter-relacionar as dimensões econômicas, políticas e sociais. Assim, a teoria do território e a capacidade de agenciamento local no processo de mudança estrutural tornaram-se viáveis, (BARQUERO, 2001, P.73).

Segundo Amaral Filho (2001) o modelo de desenvolvimento endógeno é construído a partir das bases da sociedade local, ou seja, a parte das potencialidades socioeconômicas originais do local, em vez de um modelo de desenvolvimento externo, isto é, que parte do planejamento e da intervenção conduzidos pelo estado nacional. Dessa forma, o tipo endógeno funciona com atores e ambientes que detém bons resultados internos, cujos fatores responsáveis pelo capital social geram um ambiente propulsivo para o desenvolvimento econômico. Isso é fundamental para o crescimento, pois a produção decorre de processos que viabilizam a acumulação de capital, criação e difusão de inovações no sistema produtivo, organização flexível da produção, geração de economias de aglomeração, diversificação nas cidades e o desenvolvimento das instituições. Assim, o desenvolvimento sustentável de caráter endógeno pode proporcionar a acumulação de capital, viabilizando economias de escala, com base na redução de custos de transação, favorecendo as economias diversificadas.

Além disso, para o desenvolvimento endógeno ser eficaz é necessária uma sincronia de fatores, pois exige envolvimento dos atores, ambiente ativo e pessoas com capital intelectual e social. Por isso, no caso de redes de empresas, APLs e consórcios, entre outros, o exercício da territorialidade deve transcender sua dimensão geográfica e abranger também a sua conjuntura econômica, social e política, historicamente construída e vivenciada; o dinamismo das fronteiras, intercâmbios e parcerias, enquanto construções políticas; os tipos de ligações existentes no APL (hierárquica, policêntrica e outras formas a estudar), geradas em função das especificidades locais, das imbricações externas e do capital social (MIRANDA, 2007).

Miranda (2007) salienta que as redes de relações, existentes e formadas pelos atores locais, são capazes de influenciar as tomadas de decisão e os processos de gestão das economias aglomeradas em APLs; dos mercados específicos, diretamente relacionados com a produção local - seja em termos de produtos acabados, matérias primas e outros insumos - que representam intercâmbios indispensáveis entre produtores, fornecedores e clientes; das vantagens competitivas, vocações e oportunidades, considerando as potencialidades externas e internas e compatibilizando interesses mútuos; da horizontalidade e/ou verticalidade produtiva dos APL's que caracterizam os mesmos ou são necessariamente implementadas localmente, de forma dinâmica, em função das especificidades locais e suas possibilidades em determinado momento, 
em relação à agregação de valor e suas relações com fornecedores e compradores, além da produção em escala; da especialização tecnológica e produtiva, fundamental para o avanço da acumulação econômica com base na escala, na qualidade, nos baixos custos e na competitividade; e das tecnologias, eixos principais do sucesso empresarial, as quais podem conter conhecimentos tradicionais, inovadores ou conhecimentos de ponta, dependendo das circunstâncias do contexto econômico considerado.

Diante dos constructos de Boisier et al. (1995), emerge o exemplo da Província de Valdivia no Chile, que vem obtendo sucesso no desenvolvimento endógeno com base em seis fatores:

- nos Atores. Os atores individuais podem ser identificados, nitidamente, pelo uso do software ELITE, desenvolvido no Instituto Latino-Americano e do Caribe de Desenvolvimento Econômico e Social (ILPES) para essa finalidade.

- na Cultura do Desenvolvimento, manifestada em alguns lugares pelo tipo competitivo/individualista, capaz de gerar crescimento, mas sem capacidade de gerar um verdadeiro desenvolvimento. Vários pesquisadores já expressaram unanimidade de que uma das chaves do sucesso dos distritos industriais italianos parece consistir na boa combinação microeconômica e meso-social da cooperação e da concorrência;

- nos Recursos que Peter Drucker (1993) usa também no conceito de sociedade do conhecimento, com cautela, porém firmeza, ao fazer previsões: "seria idiotice predizer, hoje, o surgimento da Sociedade do Conhecimento, do mesmo modo que teria sido prematuro vaticinar em 1776 a chegada da sociedade capitalista, sobre a qual Karl Marx escreveu cem anos mais tarde;

- nas Instituições. Uma adequada institucionalidade constitui outro fator importante na estimulação do desenvolvimento - tema favorito nos trabalhos do Prêmio Nobel da Economia Douglas North;

- nos Procedimentos. Uma adequada institucionalidade não basta. É preciso que haja uma correspondência automática entre as instituições e os procedimentos (adequados). Atualmente confunde-se, na prática, a gestão de governo com a tecnologia da gestão do desenvolvimento, pois esta última envolve a construção de um projeto político regional ou provincial, para cuja finalidade existe toda uma metodologia à disposição dos governos provinciais e regionais (BOISIER, 1992); e

- no Entorno, o qual é o último dos elementos do hexágono do desenvolvimento. Relaciona-se com tudo o que é externo à região ou à província, configurando a multiplicidade de organismos sobre os quais não se tem controle, mas com os quais a região como um todo se articula necessariamente. Este último fator diz respeito, fundamentalmente, ao mercado no sentido lato, ao Estado e ao tecido de relações internacionais. Atualmente, estas relações aparecem com renovada importância à luz de novos esquemas de cooperação internacional de caráter horizontal, ou seja, de região para região. 
Evidentemente, o desenvolvimento de um território organizado não depende apenas da existência desses seis fatores, nem da sua qualidade, mas depende, basicamente, do modo como são articulados. Uma articulação densa e inteligente produzirá, inevitavelmente, o desenvolvimento. Uma articulação difusa e aleatória impedirá o surgimento do desenvolvimento.

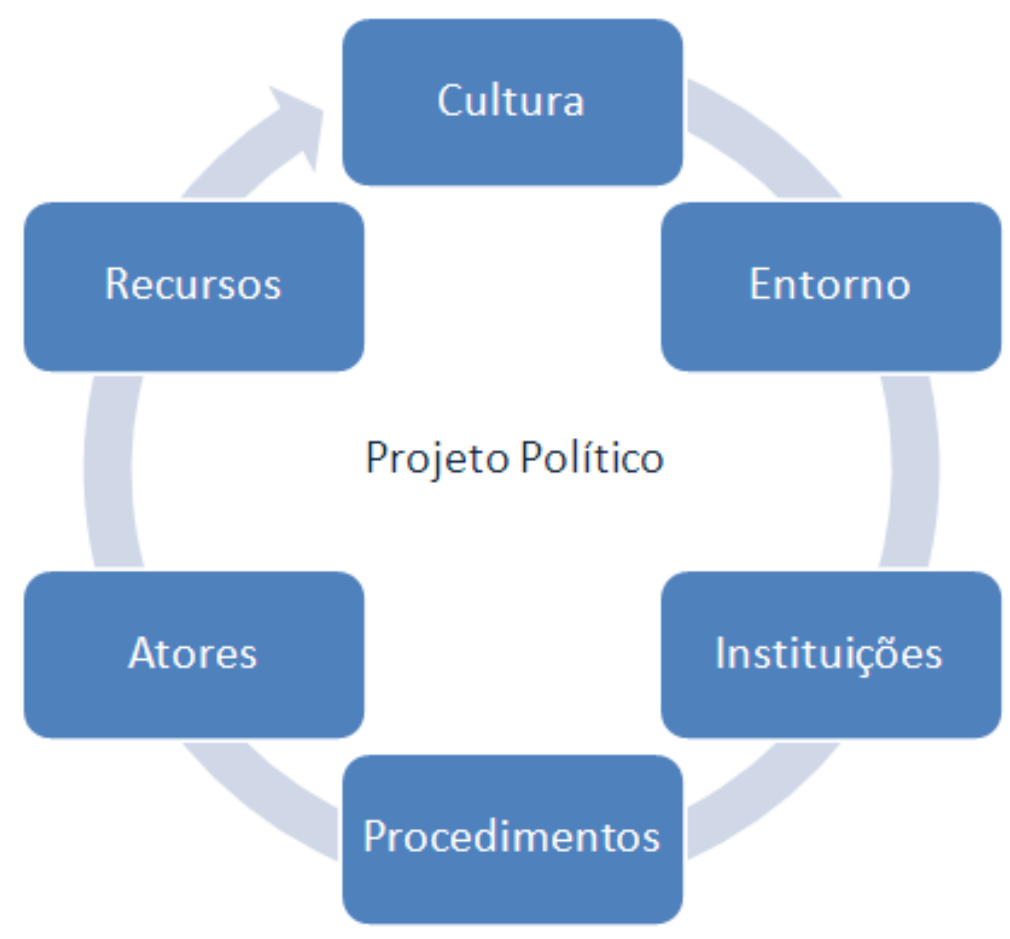

Figura 2 - Modelo de hexágono do desenvolvimento regional

Fonte: Boisier (1995)

As teorias clássicas a respeito do desenvolvimento regional, geralmente, denotam a idéia da existência de uma força motriz de caráter exógeno capaz de influenciar, por meio de encadeamentos (linkages effects), as demais atividades econômicas. Em linhas gerais, é o conhecido paradigma "centro-abaixo" devido à presença de forças impulsoras advindas das regiões centrais. Pensar em desenvolvimento regional é, antes de qualquer coisa, pensar na participação da sociedade local no planejamento contínuo da ocupação do espaço e na distribuição dos frutos do processo de crescimento.

O desenvolvimento deve ser encarado como um processo complexo de mudanças e transformações de ordem econômica, política e, principalmente, humana e social. Desenvolvimento nada mais é que o crescimento - incrementos positivos no produto e na renda - transformado para satisfazer as mais diversificadas necessidades do ser humano, tais como: saúde, educação, habitação, transporte, alimentação, lazer, dentre outras (OLIVEIRA, 2002, p.40). 
A compreensão das características e do conceito de desenvolvimento facilita a elaboração e implementação de planos de desenvolvimento nas regiões. Boisier (1989, p. 601) sugere que, para entender o processo de desenvolvimento regional, deve-se dar uma atenção especial a um conjunto de elementos - macroparâmetros - que delimitam o âmbito do planejamento do desenvolvimento regional em termos de sistemas de organização econômica, de estilos de desenvolvimento e dos conceitos hoje dominantes sobre o desenvolvimento econômico.

A proposta do referido autor não substitui, mas complementa as teorias atuais sobre o desenvolvimento econômico regional, que na sua maioria enfatizam, apenas e tão-somente, a dinâmica do crescimento em uma preocupação única de responder ao "como" e não ao "por que" da ocorrência do desenvolvimento:

\begin{abstract}
[...] o processo de crescimento econômico regional pode ser considerado [...] como essencialmente originado em forças e mecanismos exógenos à região; depende principalmente (mas não exclusivamente) do esboço das políticas macroeconômicas, do critério que guia a alocação de recursos entre as regiões e da demanda externa. Pelo contrário, o processo de desenvolvimento regional deve ser considerado, principalmente, como a internalização do crescimento e, em consequência, como de natureza essencialmente endógena (BOISIER, 1989, p.616).
\end{abstract}

Todavia, o desenvolvimento regional é o resultado de uma necessidade real, uma forma de gerir mais e melhor os fatores de desenvolvimento, tanto na otimização dos recursos como na garantia de uma maior participação dos diferentes atores. Neste contexto, é possível identificar os objetivos fundamentais do desenvolvimento regional, que se traduzem no combate às assimetrias regionais; no aproveitamento dos recursos e potencialidades endógenos das regiões; na promoção do ordenamento do território; e na garantia da participação dos cidadãos na resolução dos problemas regionais. O desenvolvimento regional ou local depende da conciliação das políticas, que impulsionam o crescimento, com os objetivos locais. A organização da sociedade local pode transformar o crescimento, advindo dos desígnios centrais, em efeitos positivos, ou melhor, em desenvolvimento para a região.

\title{
MÉTODO
}

Este estudo configura-se como uma pesquisa qualitativa descritiva (YIN, 2005). Este tipo de pesquisa permite o contato direto e indireto do pesquisador, traduzindo o sentido dos fenômenos. Por outro lado, a mesma se caracteriza como um estudo de caso, por se tratar de uma investigação empírica que aborda um fenômeno contemporâneo dentro de seu contexto da vida real, numa situação tecnicamente única em que há muito mais variáveis de interesse do que pontos de dados (YIN, 2005).

Como unidade de análise, definiu-se o COREDE/VJ por representar um Conselho que vem experimentando discreto, porém persistente crescimento, fundamentado em um planejamento considerado modelo. Para operacionalização da pesquisa, foram consultadas atas de reuniões e materiais publicados no sítio do COREDE/VJ, hospedado no portal da Universidade Regional 
Integrada do Alto Uruguai e das Missões inicialmente, fez-se uma busca nos diagnósticos técnicos e em seguida nos demais materiais publicados.

Uma vez coletados, os dados foram tabulados, classificados e codificados para a construção da Matriz SWOT, ou seja, identificação das Forças, Oportunidades, Fraquezas e Ameaças inerentes ao escopo da pesquisa.

Em um primeiro momento foram registrados enfaticamente os fatores de origem interna, enquadrados como Forças e Fraquezas locais, com o intuito de otimizar o direcionamento do foco da investigação. Numa segunda etapa, providenciou-se na matriz com os fatores externos: Oportunidades e Ameaças, cujos resultados são apresentados na próxima seção.

O Método de análise SWOT foi criado na década de 1960 por Albert Humphrey (DUGGAN, 2003), que coordenou um projeto de pesquisa na Universidade de Stanford, entre 1960 e 1969, com o objetivo de identificar os motivos pelos quais o planejamento falhava, o que resultou na criação do método S.O.F.T (Satisfactory, opportunity, fault e treat).

Segundo a metodologia S.O.F.T, a dimensão satisfactory representa aquilo que é considerado como bom no momento vigente; e a dimensão opportunity o que é bom no futuro. Por outro lado, a dimensão fault referia-se àquilo que é ruim no momento vigente; e a dimensão treat àquilo observado como ruim no futuro. Em 1964, aprimorando os fatores apresentados no modelo proposto, Albert Humphrey mudou o nome do mesmo para SWOT, por perceber que o termo weaknesses era mais adequado do que fault.

O Método SWOT (strenghts, weakenesses, opportunities and threats), tem como objetivo prover aporte para a elaboração de análises e planejamentos sobre uma determinada temática, envolvendo análises dos ambientes interno e externo à organização.

\section{O COREDE DO VALE DO JAGUARI/RS}

Em 1998, o governo do estado do Rio Grande do Sul implantou a Política Estadual de Desenvolvimento Regional, tendo como principal instrumento a Consulta Popular à população, viabilizada através dos COREDEs, a fim de possibilitar à população decidir, por voto direto, sobre a destinação de determinado percentual do orçamento estadual. Os COREDEs começaram a ser estruturados no início da década de 90 e foram institucionalizados através do Decreto-Lei no 10.283, de 17 de outubro de 1994. Inicialmente, foram criadas 21 regiões e, hoje, o Rio Grande do Sul conta com 28 COREDEs. Atualmente, cabe à Secretaria Extraordinária de Relações Institucionais do Governo Estadual a atribuição de preparar, organizar e realizar a Consulta Popular, em parceria com os COREDEs.

O planejamento do COREDE Vale do Jaguari (COREDE VJ) elaborado em convênio com a URI/Câmpus de Santiago, RS. A elaboração do Planejamento Estratégico dos nove municípios circunscritos ao COREDE Vale do Jaguari, envolveu estudos visando conhecer a realidade regional e prospectar suas alternativas de evolução socioeconômica, compreendendo o Diagnóstico Técnico, a Análise Situacional, a Aplicação da Matriz SWOT (em audiências públicas, envolvendo 150 lideranças locais), a Definição das Diretrizes Estratégicas, a Definição dos Objetivos Estratégicos (Programas, Projetos e Ações) e a Gestão do Plano. 

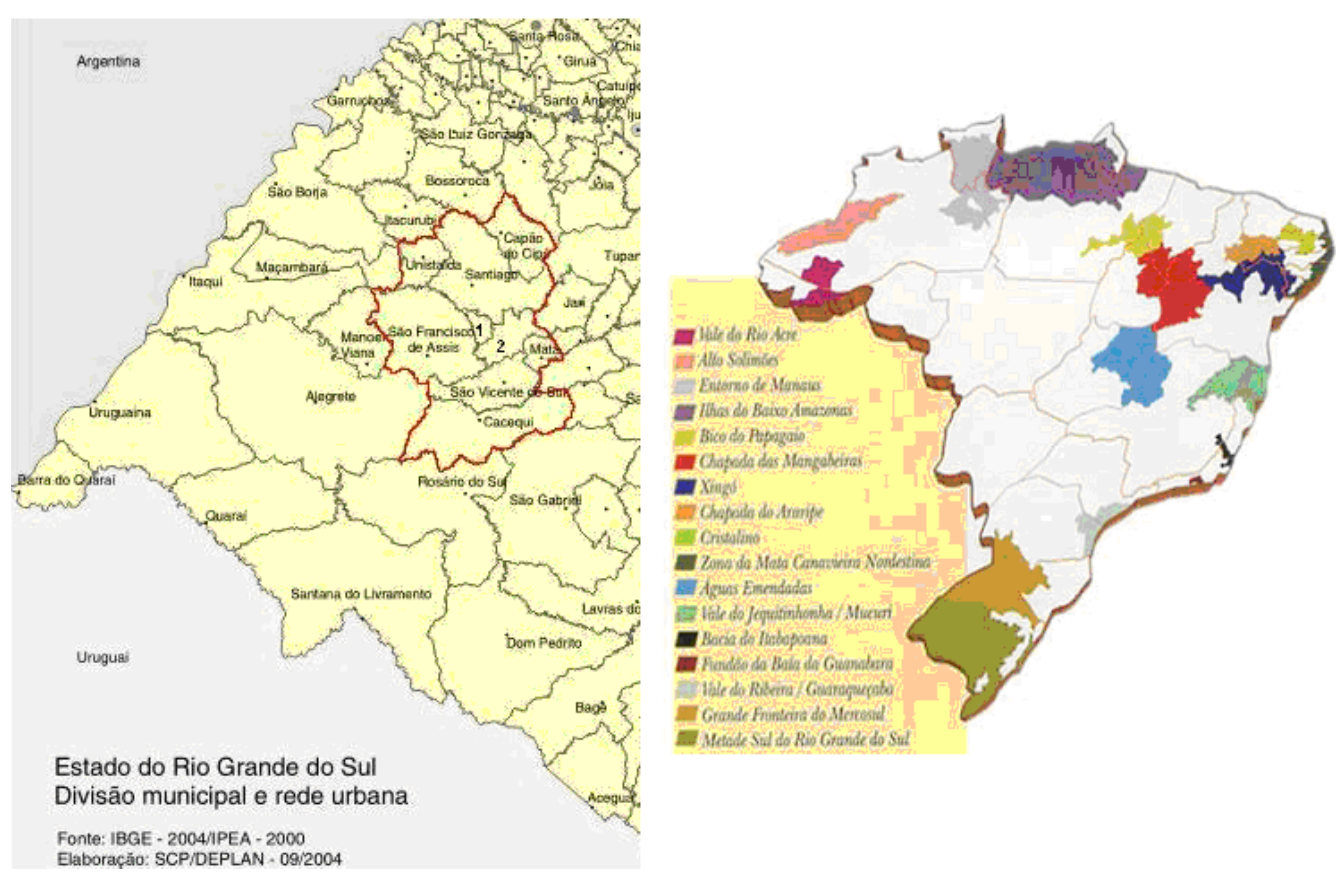

Figura 3 - Localização geográfica dos municípios Figura 4-Mesorregiões brasileiras COREDE VJ; (1) Nova Esperança do Sul; (2) Jaguari.

Fonte: IBGE (2004)

A região do COREDE Vale do Jaguari é integrada pelos municípios de Cacequi, Capão do Cipó, Jaguari, Mata, Nova Esperança do Sul, Santiago, São Francisco de Assis, São Vicente do Sul e Unistalda (Figura 3). Abrange uma área de $11.268,10 \mathrm{Km}^{2}$ (4\% do Estado), onde vivem aproximadamente 121 mil pessoas (1,12\% do Estado). São Francisco de Assis, Santiago e Cacequi, ocupam $64,71 \%$ da área e abrigam $69,89 \%$ da população regional. São Francisco de Assis é o município de maior área, e Santiago, o de maior número de habitantes. O COREDE Vale do Jaguari insere-se na Metade Sul do RS que abrange 09 COREDEs (Figura 4): Campanha, Central, Centro Sul, Fronteira Oeste, Sul, Jacuí Centro, Jaguari, Litoral, e Vale do Rio Pardo, sendo que estes últimos dois são abrangidos parcialmente. Esses conselhos são compostos de representantes dos diversos segmentos da sociedade que participam decisivamente das deliberações coletivas norteadoras do desenvolvimento regional e estadual, razão pela qual são verdadeiros pilares de sustentação do modelo de gestão regional adotado pelo Governo Estadual.

\section{PROCESSO DE PLANEJAMENTO DO COREDE VALE DO JAGUARI}

O processo de planejamento regional do COREDE Vale do Jaguari (2009), após a fase de diagnóstico, previu a construção da matriz FOFA (Fortalezas, Oportunidades, Fraquezas e Ameaças). A matriz teve como objetivo demonstrar as potencialidades, limitações e problemas com o subsídio das entrevistas e das análises bibliográfica e de informações coletadas nas 
reuniões de trabalho com as principais lideranças locais. A fase de construção da matriz FOFA consistiu de duas etapas: inicialmente foi realizada pela equipe técnica da URI, uma análise de cenário, baseada em referenciais bibliográficos; após foram definidos os pontos fortes e fracos dos municípios integrantes do COREDE Vale do Jaguari.

As Reuniões de Planejamento, realizadas nos dias 19, 20, 21 e 25 de novembro de 2009, envolveram aproximadamente 150 (cento e cinquenta) pessoas, nos municípios de Capão do Cipó, Unistalda, São Vicente do Sul, Jaguari, Cacequi, São Francisco de Assis, Mata, São Vicente do Sul e Santiago. Os encontros envolveram lideranças locais, como prefeitos, vereadores, líderes comunitários, gerentes de instituições bancárias, empresários, representantes de instituições empresariais, representantes da segurança pública, e outras autoridades locais. A coleta de dados primou-se pelo processo de planejamento participativo, conduzido pela equipe técnica da URI. Inicialmente fez-se uma apresentação do diagnóstico técnico e em seguida procedeu-se a coleta de opiniões através da metodologia de trabalho denominada METAPLAN.

Esta metodologia se fundamenta no enfoque participativo. Suas ferramentas permitem a resolução de problemas complexos, através de fichas preenchidas pelos participantes. 0 desenvolvimento sustentável dos municípios e a garantia de continuidade do planejamento regional dependem necessariamente do envolvimento e comprometimento das lideranças locais. Neste sentido, o COREDE deverá dar sustentação à descentralização das decisões e ações como estratégia fundamental e adequada para enfrentar os inúmeros problemas e desafios inerentes à operacionalização do planejamento estratégico. Outro aspecto que influenciou a escolha do processo participativo alicerça-se na necessidade de desenvolver um processo de transformação e de mudança, principalmente no aspecto comportamental dos indivíduos e, em consequência, nas suas instituições e municípios. O processo participativo potencializa a capacidade criativa das organizações, gerando idéias que poderão ser utilizadas para impulsioná-las à frente, tendo como premissa a inovação, agilidade e busca incessante de alternativas competitivas sustentáveis.

As reuniões realizadas pela equipe técnica do COREDE VJ nos seus municípios integrantes obedeceram ao seguinte roteiro:

$1^{\circ}$ - Apresentação do Diagnóstico Técnico pela Equipe de Planejamento Estratégico;

$2^{\circ}$ - Formação de Grupos interdisciplinares para discussão dos seguintes Temas: Desenvolvimento Econômico e Produtivo; Desenvolvimento Social e Capital Humano, Desenvolvimento Territorial e Capital Humano, Desenvolvimento Institucional e Gestão Pública;

$3^{\circ}$ - Definição dos Pontos Fortes e Fracos e exposição em Mural;

$4^{\circ}$ - Abertura das tarjetas e esclarecimento a todos os presentes;

$5^{\circ}$ - Encerramento das atividades e encaminhamento dos próximos passos.

\section{ANÁLISE DOS RESULTADOS DA APLICAÇÃO DA MATRIZ FOFA}


Para construção da matriz identificadora de Forças, Oportunidades, Fraquezas e Ameaças (FOFA) de âmbito regional, foram realizadas 9 reuniões que contaram com a participação de quase 150 lideranças locais atuantes em cada um dos nove municípios integrantes do COREDE Vale do Jaguari.

No primeiro momento foram registrados enfaticamente os fatores de origem interna, qual sejam Forças e Fraquezas locais, com o intuito de concentrar e otimizar o foco dos participantes. Numa segunda etapa, em escritório, contando com a participação de especialistas nas diversas áreas, completou-se a matriz com os fatores externos: Oportunidades e Ameaças (os resultados estão sistematizados nas Figuras 5, 6 e 7).

GESTÃO ECONÔMICA

Setores primário, secundário, terciário, VAB/PIB; mercado de trabalho; comércio exterior; e finanças públicas locais

\begin{tabular}{|c|c|}
\hline FORÇAS & FRAQUEZAS \\
\hline Tradição produtiva alicerçada na agropecuária & $\begin{array}{l}\text { Estrutura econômica pouco diversificada, tecido empresarial } \\
\text { majoritariamente de dimensão reduzida (com predomínio de } \\
\text { empresas de âmbito familiar) }\end{array}$ \\
\hline $\begin{array}{l}\text { Bovinocultura, ovinocultura, orizicultura, sojicultura, vitivinicultura, } \\
\text { setor coureiro calçadista e agroindústria }\end{array}$ & $\begin{array}{l}\text { Excessiva dependência econômica dos setores agropecuários e de } \\
\text { serviços }\end{array}$ \\
\hline $\begin{array}{l}\text { Recursos naturais e expressivo potencial favoráveis à exploração } \\
\text { turística }\end{array}$ & Reduzida capacitação na elaboração de novos projetos \\
\hline Comércio em persistente ascensão, especialmente em Santiago & $\begin{array}{l}\text { Produtos agro-pecuários com baixo valor agregado vendidos em boa } \\
\text { parte in natura e a preços desestimulantes }\end{array}$ \\
\hline $\begin{array}{l}\text { Comércio, administração pública e agropecuária demonstram boas } \\
\text { potencialidades }\end{array}$ & Excessivo número de produtores rurais informais (leite, etc.) \\
\hline $\begin{array}{l}\text { Boa articulação e associativismo em alguns segmentos (criadores de } \\
\text { ovinos, fruticultores e outros) }\end{array}$ & Baixo nível tecnológico na agroindústria \\
\hline $\begin{array}{l}\text { Existência de duas instituições de ensino superior presencial na } \\
\text { região }\end{array}$ & Insuficiente assistência técnica aos produtores rurais \\
\hline Abundante disponibilidade de mão-de-obra & $\begin{array}{l}\text { Falta de identidade/tradição e de infra-estrutura turística; carência de } \\
\text { mão-de-obra qualificada; reduzidas opções de produtos turísticos; } \\
\text { falta de inventários e de material de divulgação; inexpressiva } \\
\text { atratividade de novos empreendimentos; e deficiências na gestão }\end{array}$ \\
\hline
\end{tabular}

Figura 5 - Análise da gestão econômica (forças e fraquezas)

Fonte: Elaboração da equipe técnica do Corede VJ

Um dos mais graves problemas regionais detectados foi o esvaziamento da força de trabalho jovem. A população adolescente (15-19 anos) diminuiu a uma taxa de $2 \%$ a.a., desde 2000, enquanto no mesmo período, no Estado, a redução média anual foi a metade. Por sua vez, a população adolescente e jovem (15-29 anos) decresceu a quase 0,5\% a.a., enquanto que, no Estado, expandiu-se a quase 0,5\% a.a., no mesmo período. Verifica-se, a partir destes números, que a região está em processo de involução no que ela tem de mais valioso, que é o 
seu capital humano. As causas deste fenômeno de involução demográfica são multidimensionais e complexas envolvendo variáveis endógenas e exógenas de caráter econômico, social, político, cultural e ambiental, principalmente. Porém, infere-se que a falta de perspectivas regionais de qualificação profissional, de oportunidades de trabalho/empreendimento e obtenção de salário/renda, sejam os principais determinantes.

\begin{tabular}{l|l}
\hline \multicolumn{1}{c|}{ OPORTUNIDADES } & \multicolumn{1}{c}{ AMEAÇAS } \\
\hline Excelência dos solos e dos recursos hídricos & $\begin{array}{l}\text { Risco de descontinuidade político-administrativa das ações } \\
\text { planejadas e/ou em execução }\end{array}$ \\
\hline $\begin{array}{l}\text { Expansão promissora do mercado nacional, em decorrência do } \\
\text { aumento da demanda interna, em especial a originária de produtos } \\
\text { agro-industriais }\end{array}$ & $\begin{array}{l}\text { Fraca ressonância em face da insuficiente representatividade } \\
\text { político-legislativa, principalmente em nível federal }\end{array}$ \\
\hline $\begin{array}{l}\text { Boas possibilidades de ocupação de espaços nas indústrias } \\
\text { tradicionais - móveis, confecções e calçados }\end{array}$ & $\begin{array}{l}\text { Concorrência de outras regiões, especialmente onde já se pratica a } \\
\text { agricultura irrigada (e de precisão) }\end{array}$ \\
\hline $\begin{array}{l}\text { Desenvolvimento de um APL florestal/madeireiro impulsionado a } \\
\text { partir da implantação do pólo de celulose no Estado, bem como } \\
\text { pelas boas oportunidades de negócio no mercado internacional para } \\
\text { produtos de madeira reflorestada }\end{array}$ & Encolhimento dos índices de retorno do ICMS aos municípios \\
\hline Adequação do aeroporto de Santiago para embarque de produtos & Redução dos preços das commodities \\
\hline & $\begin{array}{l}\text { Barreiras ambientais e fitossanitárias por parte de países } \\
\text { compradores }\end{array}$ \\
\hline
\end{tabular}

Figura 6 - Análise da gestão econômica (oportunidades e ameaças)

Fonte: Elaboração da equipe técnica do Corede VJ

Na região, a agricultura carece de infraestrutura e de uma política de crédito que estimule a diversificação das atividades produtivas; os produtos agro-pecuários possuem baixo valor agregado e são vendidos, em boa parte, in natura e a preços desestimulantes; existe um excessivo número de produtores rurais informais e a assistência técnica a esses produtores é insuficiente; e verifica-se um inexpressivo nível de empreendedorismo no setor agropecuário (para cada 1000 pessoas ocupadas, no período 1997-2005, apenas 6 eram empreendedores (Silveira, 2010). Segundo dados do IBGE, disponíveis no banco de dados da Fundação de Economia e Estatística/RS, a lavoura permanente é representada pelas culturas de laranja, uva, tangerina e pêssego, as quais são responsáveis por quase $100 \%$ do valor da produção dos 9 municípios, em todos os tipos de cultivares dessa atividade agrícola.

Conforme apresenta-se na Figura 7, a região do COREDEVJ possui fatores potenciais muito importante para o desenvolvimento da região. Cita-se o exemplo das terras férteis e localização privilegiada, que fortalecem a economia da região, e diferencia-se de outras realidades do Estado do RS. 


\begin{tabular}{|c|c|}
\hline POTENCIALIDADES (Forças x Oportunidades) & $\begin{array}{l}\text { DESAFIOS (Fraquezas x Oportunidades) } \\
\text { RISCOS (Forças x Ameaças) } \\
\text { LIMITAÇÕES (Fraquezas x Ameaças) }\end{array}$ \\
\hline $\begin{array}{l}\text { Posição geográfica privilegiada no contexto das rotas de transporte } \\
\text { do MERCOSUL }\end{array}$ & $\begin{array}{l}\text { Base econômica ligada a atividades pouco dinâmicas e de pequeno } \\
\text { potencial para a criação de empregos diretos e indiretos }\end{array}$ \\
\hline $\begin{array}{l}\text { Solos e clima de qualidade adequada para algumas culturas, como a } \\
\text { fruticultura (uva, pêssego, pêra, melão, figo e a ameixa, dentre } \\
\text { outras) }\end{array}$ & $\begin{array}{l}\text { Atores locais historicamente têm evidenciado uma reduzida } \\
\text { capacidade no sentido de identificar e explorar oportunidades de } \\
\text { diversificação da base econômica }\end{array}$ \\
\hline $\begin{array}{l}\text { Algumas linhas de produção tradicionais da região podem ser } \\
\text { qualificadas, de forma a aumentar sua produtividade e seus efeitos } \\
\text { para o desenvolvimento regional, como é o caso da bovinocultura de } \\
\text { corte, da ovinocultura e da produção leiteira }\end{array}$ & $\begin{array}{l}\text { A agricultura familiar existente na região carece de infra-estrutura e } \\
\text { de uma política de crédito para os pequenos produtores que estimule } \\
\text { a diversificação das atividades produtivas }\end{array}$ \\
\hline $\begin{array}{l}\text { O florestamento é outra potencialidade a considerar, especialmente } \\
\text { em áreas cujos solos apresentam limitaçöes quanto à capacidade de } \\
\text { uso }\end{array}$ & $\begin{array}{l}\text { A comercialização da produção primária é outro entrave importante, } \\
\text { bem como a descapitalização dos produtores e o seu endividamento }\end{array}$ \\
\hline $\begin{array}{l}\text { Recursos naturais de expressiva relevância turística e } \\
\text { disponibilidade de excelentes áreas com potencial para o turismo } \\
\text { rural e ecológico }\end{array}$ & $\begin{array}{l}\text { Os investimentos estão comprometidos, implicando seriamente na } \\
\text { capacidade de produção de toda cadeia agropecuária: } \\
\text {-Reflexos diretos no nível de empregos da cadeia produtiva agrícola } \\
\text { e industrial. }\end{array}$ \\
\hline
\end{tabular}

Figura 7 - Análise da gestão econômica (potencialidades, desafios, riscos e limitações)

Fonte: Elaboração da equipe técnica do Corede VJ

Após análises dos resultados da matriz SWOT apresentados nas Figuras 5, 6 e 7 fasear-seá uma análise, do modelo de desenvolvimento de Boisier, que apresenta destaque e defende fatores que podem ser atribuídos a realidade do estudo. A tese do autor salienta que o desenvolvimento de um território organizado depende da existência, da articulação e das condições de manejo de seis elementos, que normalmente estão presentes em qualquer território organizado: a) atores, b) instituições, c) cultura, d) procedimentos, e) recursos, e f) entorno. Esses seis elementos, que devem ser estudados caso a caso, interagem de um modo que possa fazer com que o desenvolvimento seja resultante de uma relação densa e inteligentemente articulada, mediante um projeto político regional (BOISIER, 1995). A partir das análises dos elementos comuns ao desenvolvimento regional apresentado pelo autor, e juntamente com as análises SWOT apresentadas na pesquisa, pôde-se ser considerados os seguintes fatores na região do COREDE VJ:

O entorno do COREDE-VJ está localizado em região próxima da fronteira dos países Argentina e Uruguai, sendo considerado um lugar privilegiado no contexto de transportes, sendo muito importante para o desenvolvimento da região.

Na cultura a região destaca-se por sua população ser constituída de imigrantes de origem Italiana, Alemã, Portugueses e Espanhóis. Os aspectos culturais dessa população estão ligados à produção de comoditites agrícolas (soja, trigo e milho), e na produção agropecuária (bovinocultura, ovinocultura etc). Cabe destacar, que os municípios presente nessa região, 
possuem algumas diferenças econômicas e algumas culturas que encontram-se em crescimento, como é caso do município de Jaguari - especializado na produção de bebidas (vinhos, cachaça), Nova Esperança Sul - indústria do Couro, e Capão do Cipó - com grandes propriedades agrícolas.

Quanto a instituições, a região é composta por Instituições de Ensino Superior - IES privadas e públicas. Dentre os municípios participantes destacam-se três. Jaguari e São Vicente do Sul que possuem o Instituto Federal Farroupilha, com cursos técnicos e extensão, graduação e especialização, sendo um diferencial na formação de novos profissionais voltados para desenvolvimento e fomento da economia regional; e, o município de Santiago, que possui a maior instituição, a Universidade Regional Integrada - URI, que possui cursos de graduação e pósgraduação.

No que se refere a recursos, a região do COREDE-VJ encontra-se com algumas carências, que devem ser planejadas para busca de melhores resultados. O estudo revelou que um dos maiores problemas está relacionado à dependência da população pelo setor primário, considerado um dos pilares da economia regional. Uma vez que, esse setor, liderado pela produção da soja e criação bovina, (em grande maioria dos munícipios pertencentes ao COREDEVJ) estão sujeitos ao comportamento do clima da região, aliados aos fatores da escassez de chuvas, resultando em maiores despesas e custos na propriedade, bem como, à baixa produção de grãos. Já no que se refere a recursos humanos, a região encontra-se no processo de planejamento, pois com o apoio do Instituto Federal Farroupilha (Campus de São Vicente do Sul e Jaguari) e alguns órgãos como o SEBRAE e SENAI, com foco a capacitação e treinamento dos produtores (considerados produtores da agricultura familiar) para melhorar a produção e gestão de suas atividades. O objetivo dessas instituições é integrar os produtores nas das cadeias produtivas locais e incentivar o empreendedorismo, fomentando emprego e renda.

Os procedimentos do COREDE-VJ estão aliados à gestão das atividades rurais e empresariais. A região é formada na sua grande maioria pelos proprietários. Nos últimos anos com os avanços das Instituições de ensino, principalmente com o apoio do Instituto Federal, as propriedades e empresas estão sendo aperfeiçoadas, por meio de uma gestão de liderança, procedimentos administrativos seguindo as legislações vigentes e técnicas de mercado, bem como uma tomada de decisão com maior eficiência.

Quanto aos atores. O estudo revelou que os lideres regionais estão voltados para o processo participativo de planejamento, visando desencadear e manter um ciclo pró-ativo, principalmente no perfil comportamental dos diversos atores, pois eles fazem parte de organizações nas esferas sociais, empresariais, politicas etc.

Quanto à tese de Barquero (2001) definem-se quatro eixos no modelo proposto: a) sistemas locais de empresas, b) entornos inovadores, c) áreas rurais e d) espaço de inovação e aprendizagem. Verifica-se que são eixos que estão presentes nas propostas de Boisier (1995), porém contempla uma abordagem voltada para o desenvolvimento empresarial, sob a ótica de sistemas de inovação e aprendizagem. 


\section{CONCLUSÕES}

O presente estudo teve como objetivo relata à experiência do Conselho Regional de Desenvolvimento do Vale do Jaguari/RS na elaboração do Planejamento Estratégico Regional, tentando associá-la à ótica dos modelos de desenvolvimento de Barquero (2001) e Boisier (1995), desde o diagnóstico das potencialidades e carências apresentadas pela região e discutidas amplamente, principalmente pela equipe técnica e lideranças dos municípios abrangidos.

Verificou-se que o desenvolvimento local está associado a iniciativas inovadoras e mobilizadoras da coletividade, articulando as potencialidades locais com as condições dadas pelo contexto. Como diz Arto Haveri (1996), as comunidades procuram utilizar suas características específicas e suas qualidades superiores, para se especializarem nos campos em que têm vantagens comparativas com relação às outras regiões.

O trabalho de quase 18 anos na gestão dos processos de desenvolvimento local e regional acabou sendo reconhecido e respeitado, mas somente após diversas manifestações do Fórum dos COREDEs. Apesar dessa sobreposição de regionalização, os COREDEs caminham a passos largos para a sua efetiva consolidação enquanto instâncias de planejamento e articulação regional, pois começam a ser reconhecidos e respeitados pela sociedade, como evidencia o crescimento da participação nos processos da Consulta Popular.

No novo paradigma do desenvolvimento as vantagens competitivas se deslocam da abundância de recursos naturais, dos baixos salários e das reduzidas exigências ambientais predominantes no ciclo expansivo do pós-guerra - para a liderança e domínio do conhecimento e da informação (tecnologia e recursos humanos); e para a qualidade e excelência dos produtos e serviços (PEREZ e PEREZ, 1984). Um dos mais graves problemas regionais detectados no COREDE Vale do Jaguari foi o esvaziamento da força de trabalho jovem, que diminuiu a uma taxa de $2 \%$ a.a., desde 2000, enquanto no mesmo período, no Estado, a redução média anual foi exatamente a metade. Por sua vez, a população adolescente e jovem (15-29 anos) decresceu a quase 0,5\% a.a., enquanto que, no Estado, expandiu-se a quase 0,5\% a.a., no mesmo período. Verifica-se, então, que a região está em processo de involução no que ela tem de mais valioso que é o seu capital humano. As causas deste fenômeno são multidimensionais e complexas e envolvem variáveis econômicas, sociais, políticas, culturais e ambientais. Porém, a falta de perspectivas regionais de qualificação profissional, de oportunidades de trabalho/empreendimento e obtenção de salário/renda são os principais fatores determinantes.

O modelo de desenvolvimento endógeno é fundamental para qualquer organização. A abordagem e o referencial expresso por Barquero (2001) viabilizam as discussões acerca do desenvolvimento. Esta temática tem alimentado, nas últimas décadas, discussões e ações que instigam uma nova sociedade, com formas diferentes de organização e de representação dos diversos interesses, em função do próprio desenvolvimento organizacional e político das diversas camadas sociais. Esta nova sociedade, por sua vez, exige novos comportamentos da esfera pública, dos técnicos e das organizações civis, impondo posturas mais dialógicas e consultivas, em relação às necessidades de mudança e escolha dos melhores caminhos para mudar. Concomitantemente, o espaço político passa a ser ocupado por grupos distintos e novas 
maneiras de atuação, que buscam substituir as formas antigas de representação dos diversos interesses de diferentes coletivos. Salientam-se, igualmente, as circunstâncias da pobreza regional associada à devastação dos recursos naturais, que induzem à discussão participativa do desenvolvimento local em bases ambiental, econômica e social sustentáveis.

\section{REFERÊNCIAS}

1. ALLEBRANDT, Sérgio L. A cidadania e o processo de desenvolvimento local e regional: um estudo sobre a atuação dos conselhos municipais e regionais de desenvolvimento do RS, de 1990 a 2007. Santa Cruz do Sul, 2007 [projeto de tese].

2. AMARAL FILHO, J. A endogeneização no desenvolvimento econômico regional e local. Planejamento e Políticas Públicas. n. 23, p. 261-286, jun. 2001.

3. BARQUERO, Antonio. Desenvolvimento endógeno em tempos de globalização. Porto Alegre: Editora da Universidade, FEE, 2001.

4. BOISIER, S. et Alli. Sociedad civil, actores sociales y desarrollo regional. - Santiago de Chile: ILPES/DPPR, 1995.

5. BOISIER, S. Política econômica, organização social e desenvolvimento regional. In: HADDAD, P. R. (Org.), 1989.

6. BOISIER, Sérgio. Desenvolvimento. In: Siedenberg, D. R. Dicionário desenvolvimento regional. Santa Cruz do Sul: EDUNISC, 2006.

7. BRESSER PEREIRA, Luiz Carlos. Plano diretor da reforma do aparelho do Estado. Brasília, 1995.

8. DUGGAN, William. The art of what works: How success really happens, McGraw-hill: 1 edition. 2003.

9. FERNANDES, José. Considerações sobre os Conselhos Regionais de Desenvolvimento propostos no Programa. Revista POVO GRANDE DO SUL - Governo Alceu Collares/João Gilberto. Santa Maria, 1991.

10. GOVERNO DO ESTADO DO RS. Decreto $\mathrm{N}^{\circ}$ 45.593, de 10.04.08. Porto Alegre, 2008.

11. INSTITUTO BRASILEIRO DE GEOGRAFIA E ESTATISTICA - IBGE. Produtos IBGE. 2004. Disponível em <www.ibge.gov.br/home/geociencias/cartografia/territ_doc1.sht - 11k> Acesso em Abril/2011.

12. LIMA ANDRADE, J. R. Uma estratégia alternativa de desenvolvimento regional: o turismo no Estado de Sergipe. Curitiba, 1997. Dissertação (Mestrado) - UFPR.

13. MIRANDA, Henrique e all. Diagnóstico rápido participativo das reservas de desenvolvimento sustentável Alcobaça e Pucuruí-Ararão. Belém, convênio SECTAM / ELETRONORTE / POEMA, 2007.

14. MORAES, Jorge Luiz Amaral de. Capital social e políticas públicas para o desenvolvimento regional sustentável. Revista Centro de Ciências Administrativas, UNIFOR. Fortaleza, v. 9, n. 2, p. 196-204, dez. 2003.

15. OLIVEIRA, Gilson Batista de. Uma discussão sobre o conceito de desenvolvimento. Revista da FAE, Curitiba, v.5, n.2, p.41-48, maio/ago. 2002. 
16. SILVEIRA, João Tusi da. Integração da piscicultura com a fruticultura fertirrigada em pequenas propriedades rurais do Vale do Jaguari/RS. Brasília. Prêmio Nacional de Desenvolvimento Regional 2010 - N.059_Cod000528; 2010.

17. TOLOSA, Hamilton C. Pólos de crescimento: teoria e política econômica. São Paulo. EGRT. 1972.

18. YIN, R. K. Estudo de Caso: Planejamento e métodos. Tradução de Daniel Grassi. 3 ed. Porto Alegre: Bookman, 2005. 